OPEN ACCESS

Edited by: Milena De Felice,

University of Sheffield, United Kingdom

Reviewed by: Marco Carotenuto, Università degli Studi della Campania

Luigi Vanvitelli Caserta, Italy Marcelo M. Valença,

Universidade Federal de

Pernambuco, Brazi

*Correspondence: László Vécsei

vecsei.laszlo@med.u-szeged.hu

Specialty section:

This article was submitted to Headache Medicine and Facial Pain, a section of the journal

Frontiers in Neurology

Received: 30 October 2017 Accepted: 26 December 2017 Published: 16 January 2018

Citation:

Körtési T, Tuka B, Tajti J, Bagoly T,

Fülöp F, Helyes Zs and Vécsei L

(2018) Kynurenic Acid Inhibits the

Electrical Stimulation Induced

Elevated Pituitary Adenylate

Cyclase-Activating Polypeptide

Expression in the TNC.

Front. Neurol. 8:745.

doi: 10.3389/fneur.2017.00745

\section{Kynurenic Acid Inhibits the Electrical Stimulation Induced Elevated Pituitary Adenylate Cyclase-Activating Polypeptide Expression in the TNC}

\author{
Tamás Körtési', Bernadett Tuka², János Tajti', Teréz Bagoly³, Ferenc Fülöp $p^{4,5}$, \\ Zsuzsanna Helyes ${ }^{3,6,7}$ and László Vécsei ${ }^{1,2 *}$
}

'Faculty of Medicine, Department of Neurology, Albert Szent-Györgyi Clinical Center, University of Szeged, Szeged, Hungary, ${ }^{2}$ MTA-SZTE Neuroscience Research Group, University of Szeged, Szeged, Hungary, ${ }^{3}$ Faculty of Medicine, Department of Pharmacology and Pharmacotherapy, University of Pécs, Pécs, Hungary, ${ }^{4}$ Faculty of Pharmacy, Institute of Pharmaceutical Chemistry, University of Szeged, Szeged, Hungary, ${ }^{5}$ MTA-SZTE Stereochemistry Research Group, Hungarian Academy of Sciences, Szeged, Hungary, ${ }^{6}$ János Szentágothai Research Center, University of Pécs, Pécs, Hungary, ${ }^{7}$ MTA-PTE NAP B Chronic Pain Research Group, University of Pécs, Pécs, Hungary

Background: Migraine is a primary headache of imprecisely known mechanism, but activation of the trigeminovascular system (TS) appears to be essential during the attack. Intensive research has recently focused on pituitary adenylate cyclase-activating polypeptide (PACAP) and the kynurenine systems as potential pathogenic factors.

Aim: We investigated the link between these important mediators and the effects of kynurenic acid (KYNA) and its synthetic analog (KYNA-a) on PACAP expression in the rat trigeminal nucleus caudalis (TNC) in a TS stimulation model related to migraine mechanisms.

Methods: Adult male Sprague-Dawley rats were pretreated with KYNA, KYNA-a, the NMDA receptor antagonist MK-801, or saline (vehicle). Next, the trigeminal ganglion (TRG) was electrically stimulated, the animals were transcardially perfused following $180 \mathrm{~min}$, and the TNC was removed. In the TNC samples, 38 amino acid form of PACAP

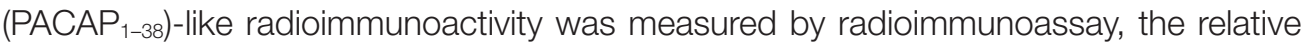
optical density of preproPACAP was assessed by Western blot analysis, and PACAP ${ }_{1-38}$ mRNA was detected by real-time PCR.

Results and conclusion: Electrical TRG stimulation resulted in significant increases of PACAP $_{1-38}-\mathrm{LI}$, preproPACAP, and PACAP ${ }_{1-38}$ mRNA in the TNC. These increases were prevented by the pretreatments with KYNA, KYNA-a, and MK-801. This is the first study to provide evidence for a direct link between PACAP and the kynurenine system during TS activation.

Keywords: migraine, trigeminovascular system, pituitary adenylate cyclase-activating polypeptide, kynurenic acid, MK-801 


\section{INTRODUCTION}

Migraine is a neurovascular primary headache disorder with a complex genetic background $(1,2)$, the pathomechanism of which is still not fully understood. One of the proposed mechanisms of the disease is the activation and sensitization of the trigeminovascular system (TS). However, central sensitization and hyperexcitability due to excessive glutamate release are also suspected to be involved in the development and persistence of pain.

Calcitonin gene-related peptide (CGRP) is one of the main regulators of the TS, and the recently identified pituitary adenylate cyclase-activating polypeptide (PACAP) also plays key roles (3-6). In migraineurs, the level of CGRP in the peripheral blood is increased during a migraine attack compared with the interictal period (4). A very similar observation has recently been made for PACAP as well, suggesting a potential biomarker function of PACAP in migraine (7). In addition, similarly to CGRP (8), intravenous administration of the 38 amino acid form of PACAP $\left(\mathrm{PACAP}_{1-38}\right)$ provoked headache and vasodilatation, both in healthy participants and migraine sufferers, whereas it delayed migraine-like attacks only in migraineurs (9-11).

In experimental conditions, intraperitoneal administration of PACAP $_{1-38}$ evoked marked photophobia, meningeal vasodilatation and increased the number of c-fos-positive activated neurons in the spinal trigeminal nucleus caudalis (TNC) in wild type, but not in PACAP ${ }_{1-38}$-deficient mice (12). In line with this, an increased concentration of PACAP ${ }_{1-38}$ was detected in the TNC after the activation of the TS in different animal models (13).

Interesting and promising endogenous regulators of glutamatergic neurotransmission include certain metabolites of the kynurenine pathway formed during the catabolism of tryptophan. Some of these metabolites are neuroactive and play essential roles in the modulation of $\mathrm{N}$-methyl-D-aspartate glutamate receptor (NMDAR) function. Since glutamate-induced overexcitation plays a significant role in a number of neuronal diseases, the kynurenine system has recently become the subject of intense neurobiological research (14).

Kynurenic acid (KYNA), an endogenous NMDAR antagonist, is one of the end products of this pathway, which can dosedependently inhibit the activation and sensitization of TS (15). However, the penetration of KYNA across the blood-brain barrier is very limited, necessitating the development of synthetic analogs with potentially better pharmacokinetic properties to exploit its

\footnotetext{
Abbreviations: BSA, bovine serum albumin; CFA, complete Freund's adjuvant; CGRP, calcitonin gene-related peptide; EDTA, ethylenediaminetetraacetic acid; ES, electrical stimulation; ES-TRG, electrical stimulation of the TRG; IQRs, interquartile ranges; KAT II, kynurenine aminotransferase II; KYNA, kynurenic acid; KYNA-a, kynurenic acid synthetic analog; MAPK, mitogen-activated protein kinase; MCA, middle cerebral artery; MMA, middle meningeal artery; NMDAR, $\mathrm{N}$-methyl-D-aspartate glutamate receptor; nNOS, neuronal nitrogen-monoxide synthase; NTG, nitroglycerin; PACAP, pituitary adenylate cyclase-activating polypeptide; PACAP $_{1-38}, 38$ amino acid form of PACAP; PBS, phosphate-buffered saline; RIA, radioimmunoassay; RT-PCR, real-time polymerase chain reaction; SDS, sodium dodecyl sulfate; TBST, Tris-buffered saline containing Tween 20; TNC, trigeminal nucleus caudalis; TRG, trigeminal ganglion; TS, trigeminovascular system; TSH, thyroid-stimulating hormone; VIP, vasoactive intestinal polypeptide.
}

therapeutic potential. In a chemically induced animal model of migraine, a derivative of KYNA was able to inhibit nitroglycerin (NTG)-induced increase of c-fos (16) and CGRP (17) expression in rat TNC. Furthermore, the same KYNA analog promoted an anti-inflammatory response in the trigeminal ganglion (TRG) in a complete Freund's adjuvant (CFA)-induced model of dural neuroinflammation (18).

To date, only a few studies have provided evidence for an association between PACAP and the NMDAR. Calcium influx through the NMDAR is an important mediator of PACAP expression, inducing gene transcription via the mitogen-activated protein kinase signaling cascade (19). PACAP has been demonstrated to enhance the functional coupling of neuronal nitrogen-monoxide synthase and the NMDAR in models of both inflammatory and neuropathic pain (20).

Based on all these recent findings, the aim of this study was to investigate a potential association between the KYNA system and PACAP expression, with particular regard to NMDAR activation and a possible novel therapeutic function for the stable KYNA analog in terms of its ability to influence migraine-related elevation of PACAP levels.

\section{MATERIALS AND METHODS}

\section{Animals}

The study used 76 young adult (10-12 weeks old) male SpragueDawley rats for the experiments; 18 intact non-stimulated animals in the control group and a total of 58 animals in the groups undergoing electrical stimulation of the TRG (ES-TRG) to model TS activation in migraine. The animals were bred and maintained under standard laboratory conditions on a 12- to 12-h light cycle at $24 \pm 11^{\circ} \mathrm{C}$ and approximately $50 \%$ relative humidity in the Laboratory Animal House of the Department of Neurology. The rats had free access to standard rat chow and water.

\section{Ethics}

All experimental procedures performed in this study complied fully with the guidelines of Act 1998/XXVIII of the Hungarian Parliament on Animal Experiments (243/1988) and with the recommendations of the International Association for the Study of Pain and European Communities Council (86/609/ECC). The studies were in harmony with the Ethical Codex of Animal Experiments and were approved by the Ethics Committee of the Faculty of Medicine, University of Szeged, XXIV./352/2012.

\section{Drugs}

MK-801 and KYNA were obtained from Sigma-Aldrich Corporation (St. Louis, MO, USA). The analog of KYNA (KYNA-a) was synthesized by Prof. Fülöp Ferenc and his research team in the Department of Pharmaceutical Chemistry, University of Szeged. KYNA was administered at $189.17 \mathrm{mg} / \mathrm{kg}$ body weight, MK-801 at $4 \mathrm{mg} / \mathrm{kg}$ body weight, and KYNA-a at $295.76 \mathrm{mg} / \mathrm{kg}$ body weight dose. The substances were dissolved in $1.5 \mathrm{ml}$ of physiological saline solution, and $\mathrm{pH}$ was adjusted with sodium hydroxide and hydrogen chloride. 


\section{Experimental Protocol}

Five animal groups were created: one non-stimulated control group and four ES-TRG groups with different pretreatments. The group pretreated with vehicle (physiological saline i.v.) was used as the negative control, whereas that pretreated with MK-801 (a known selective NMDAR antagonist) served as the positive ES-TRG control. Two additional groups were pretreated with KYNA and KYNA-a, respectively. The structural formulae of KYNA and KYNA-a are presented in Figure 1. All drugs were dissolved in $1.5 \mathrm{ml}$ physiological saline. After optimization of $\mathrm{pH}$, the solution was supplemented with physiological saline to a total volume of $2 \mathrm{ml}$.

First, the rats were anesthetized with intraperitoneal $4 \%$ chloral hydrate solution ( $10 \mathrm{ml} / \mathrm{kg}$ bw dose), and the anesthesia was maintained throughout the experiment. After intravenous administration of the pretreatments, the animals were placed in a stereotaxic setup. The head was fixed and the right TRG was localized. A stimulating electrode (FHC concentric bipolar electrode, OP: $200 \mu \mathrm{m}$ SS; IP: $50 \mu \mathrm{m}$ Pt/lr) was introduced into the TRG, and electrical stimulation (ES) was performed according to the following parameters: duration: $30 \mathrm{~min}$; stimulation rate: $10 \mathrm{~Hz}$;

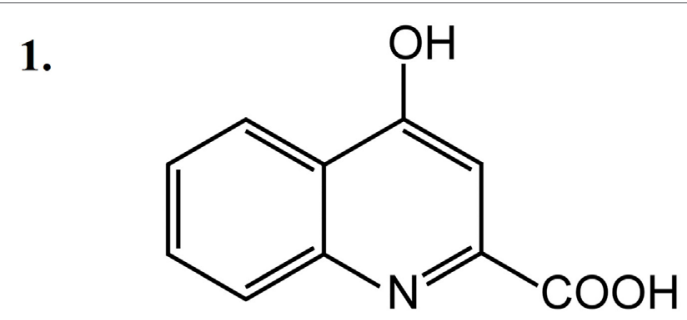

2.

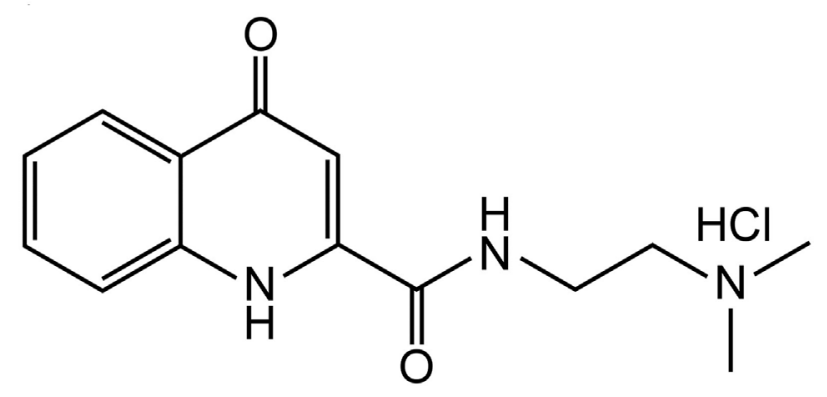

FIGURE 1 | Structural formulae of kynurenic acid (1) and kynurenic acid synthetic analog (2). current: $1 \mathrm{~mA}$; stimulation mode: continuous. Results of our previous studies suggested that the concentration of PACAP ${ }_{1-38}$ in the central nervous system is highest $3 \mathrm{~h}$ after the ES-TRG; therefore, transcardial perfusion of the animals with $200 \mathrm{ml}$ phosphatebuffered saline was initiated $180 \mathrm{~min}$ after stimulation, followed by the dissection of the TNC (13). In the non-stimulated group, perfusion and dissection were carried out following anesthesia. After preparation, the samples were stored at $-80^{\circ} \mathrm{C}$ until further use. The concentration of $\mathrm{PACAP}_{1-38}$ was measured by radioimmunoassay (RIA), the relative optical density of preproPACAP was analyzed by Western blot, and the relative gene expression of PACAP ${ }_{1-38}$ was determined by real-time polymerase chain reaction (RT-PCR). The analytical methods and their respective subject numbers are presented in Table $\mathbf{1}$.

\section{Radioimmunoassay}

The frozen samples were weighed and homogenized in $1 \mathrm{ml}$ icecold double-distilled water with a manual Potter homogenizer. The homogenates were centrifuged at 10,000 rpm for $10 \mathrm{~min}$ and then at 12,000 rpm for an additional $10 \mathrm{~min}$, and $25 \mu \mathrm{l}$ samples of the supernatants were used for RIA measurements. The tracer was mono- ${ }^{125} \mathrm{I}_{\text {-labeled }} \mathrm{PACAP}_{1-38}$ prepared in our laboratory. The synthetic peptide was used as the RIA standard in concentrations ranging from 0 to $2,000 \mathrm{fmol} / \mathrm{ml}$. The assay buffer was composed of $0.05 \mathrm{M}$ ( $\mathrm{pH} 7.4)$ phosphate buffer containing $0.1 \mathrm{M}$ sodium chloride, $0.25 \%(\mathrm{w} / \mathrm{v})$ bovine serum albumin (BSA), and $0.05 \%$ $(\mathrm{w} / \mathrm{v})$ sodium azide. The anti-PACAP ${ }_{1-38}$ (Abcam, ab35342; Lot. No.: GR48676-4; $100 \mu \mathrm{l}, 1: 10,000$ dilution), the RIA tracer $(100 \mu \mathrm{l}$, $3,000 \mathrm{cpm} /$ tube), and the standards or samples of unknown concentration $(100 \mu \mathrm{l})$ were injected into polypropylene tubes containing $700 \mu \mathrm{l}$ assay buffer ( $1 \mathrm{ml}$ total volume). After incubation for $48-72 \mathrm{~h}$ at $4^{\circ} \mathrm{C}$, the antibody-bound peptide was separated from the free peptide by the addition of $100 \mu \mathrm{l}$ separating solution $(10 \mathrm{~g}$ charcoal, $1 \mathrm{~g}$ dextran, and $0.5 \mathrm{~g}$ commercial nonfat milk powder dissolved in $100 \mathrm{ml}$ distilled water). Following centrifugation at $3,000 \mathrm{rpm}$ at $4^{\circ} \mathrm{C}$ for $20 \mathrm{~min}$, the contents of the tubes were gently decanted, and the radioactivity of the precipitates was measured in a gamma counter (gamma, type: NZ310). PACAP ${ }_{1-38}$-like immunoreactivities of the samples were calculated from the calibration curve and expressed as fentomoles per milligram wet tissue $(7,13)$.

\section{Western Blot Analysis}

The samples were sonicated in ice-cold buffer containing $50 \mathrm{mM}$ Tris- $\mathrm{HCl}, 150 \mathrm{mM} \mathrm{NaCl}, 0.1 \%$ Igepal, $0.1 \%$ cholic acid, $2 \mathrm{mg} / \mathrm{ml}$

TABLE 1 | The applied analytical methods and their respective subject number

\begin{tabular}{|c|c|c|c|c|c|c|c|c|}
\hline \multicolumn{3}{|c|}{ Radioimmunoassay } & \multicolumn{3}{|c|}{ Western blot analysis } & \multicolumn{3}{|c|}{ Real-time PCR } \\
\hline Treatment & Electrical stimulation of the TRG (ES-TRG) & $n$ & Treatment & ES-TRG & $n$ & Treatment & ES-TRG & $n$ \\
\hline- & - & 7 & - & - & 6 & - & - & 5 \\
\hline $0.9 \% \mathrm{NaCl}$ & + & 7 & $0.9 \% \mathrm{NaCl}$ & + & 6 & $0.9 \% \mathrm{NaCl}$ & + & 5 \\
\hline Kynurenic acid synthetic analog & + & 7 & Kynurenic acid (KYNA) & + & 6 & KYNA & + & 5 \\
\hline- & & & KYNA-a & + & 6 & KYNA-a & + & 5 \\
\hline- & & & MK-801 & + & 6 & MK-801 & + & 5 \\
\hline
\end{tabular}


leupeptin, $2 \mathrm{mM}$ phenylmethylsulphonyl fluoride, $1 \mathrm{mg} / \mathrm{ml}$ pepstatin, $2 \mathrm{mM}$ ethylenediaminetetraacetic acid, and $0.1 \%$ sodium dodecyl sulfate (SDS). After homogenization, the samples were centrifuged at $12,000 \mathrm{rpm}$ for $10 \mathrm{~min}$ at $4^{\circ} \mathrm{C}$, and supernatants were aliquoted and stored at $20^{\circ} \mathrm{C}$ until use. The protein concentration was determined by the BCA Protein Assay Kit using BSA as the standard. Before protein separation, each sample was mixed with the sample buffer and denatured by boiling for $5 \mathrm{~min}$. Equal amounts of protein samples (20 mg/lane) were separated by standard SDS polyacrylamide gel electrophoresis on 10\% Tris-Glycine gel and electrotransferred onto an AmershamHybond-ECL nitrocellulose membrane (0.45-mm pore size). We used the Page Ruler Prestained Protein Ladder $(10-170 \mathrm{kDa})$ to define approximate molecular weights. Following blotting, the membranes were blocked for $1 \mathrm{~h}$ at room temperature in Tris-buffered saline containing Tween 20 (TBST) and 5\% nonfat dry milk powder. Subsequently, the membranes were incubated in TBST containing $1 \%$ nonfat dry milk and anti-PACAP antibody (against the C terminal; ab174982, dilution: 1:500, incubation parameters: overnight, $4^{\circ} \mathrm{C}$ ), antiglyceraldehyde 3-phosphate dehydrogenase (GAPDH) antibody (D16H11, dilution: 1:1,000, incubation parameters: overnight, room temperature). The following day, the membranes were incubated in TBST containing $1 \%$ nonfat dry milk powder and horseradish peroxidase-conjugated goat anti-rabbit secondary antibody (sc-2030, Santa Cruz Biotechnology) for $2 \mathrm{~h}$ at room temperature. The protein bands were revealed with SuperSignal West Pico Chemiluminescent Substrate using Carestream Kodak BioMax Light film.

\section{Real-time PCR}

For RT-PCR analysis, total RNA was isolated from the TNC with Trizol, according to the manufacturer's protocol. RNA concentrations were determined using a MaestroNano spectrophotometer, and the verification of RNA integrity was performed by gel electrophoresis, using $1 \%$ agarose gel. cDNA was synthesized from $1 \mu \mathrm{g}$ total RNA with random hexamer primers by RevertAid First Strand cDNA Synthesis Kit (Thermo Scientific, USA). The produced cDNA was stored at $-20^{\circ} \mathrm{C}$ until further use. The RT-PCR was performed on a CFX 96 Real-Time System (Bio-Rad, USA) to detect changes in mRNA expression, using forward (5'-CCTACCGCAAAGTCTTGGAC-3') and reverse (5'-TTGACAGCCATTTGTTTTCG-3') primers designed for $\mathrm{PACAP}_{1-38}$. Thermal cycling conditions were $95^{\circ} \mathrm{C}$ for $2 \mathrm{~min}$ followed by 40 cycles of $95^{\circ} \mathrm{C}$ for $10 \mathrm{~s}$ and $60^{\circ} \mathrm{C} 30 \mathrm{~s}$. The relative mRNA level was calculated by the $2^{-\Delta \Delta C t}$ method. A pre-optimized primer and probe assay for $18 \mathrm{~S}$ rRNA was used as an endogenous control (Applied Biosystems, USA).

\section{Statistical Analysis}

The Shapiro-Wilk test was used to determine the distribution of data. It shows that our data do not follow the normal distribution so after the Kruskal-Wallis test we used the Tukey post hoc test to analyze the results. A probability level of $p<0.05$ was considered significant. Median \pm interquartile ranges were represented in the box-plot figures.

\section{RESULTS}

\section{Electrical TRG-Stimulation-Induced PACAP $_{1-38}$-LI Increase in the TNC Is Prevented by KYNA-a Pretreatment}

Electrical stimulation of the TRG resulted in a significant increase of $\mathrm{PACAP}_{1-38}$ - $\mathrm{LI}$ in the TNC of the vehicle-treated group $(27.49 \mathrm{fmol} / \mathrm{mg})$ compared with the intact non-stimulated control group $(19.31 \mathrm{fmol} / \mathrm{mg} ; p<0.05)$. KYNA-a-pretreatment prevented this ES-TRG-evoked elevation $(14.68 \mathrm{fmol} / \mathrm{mg})$ when compared with the stimulated, vehicle-treated animals $(p<0.01)$ (Figure 2).

\section{Electrical TRG-Stimulation-Induced preproPACAP Increase in the TNC Is Prevented by KYNA-a, KYNA, and MK-801 Pretreatment}

A significant increase in the relative optical density of preproPACAP protein was observed in the vehicle-treated ES-TRG group (1.78) as compared with the non-stimulated control group $(0.81 ; p<0.001)$. The relative optical density values of preproPACAP in the ES-TRG groups pretreated with KYNA (0.74), KYNA-a (0.51), or MK-801 (1.04) were significantly reduced compared with the vehicle-treated ES-TRG group $(p<0.001)$.

\begin{tabular}{|c|c|c|c|c|c|c|c|c|}
\hline \multicolumn{2}{|c|}{ Radioimunoassay } & \multicolumn{3}{|c|}{ Western blot analysis } & \multicolumn{3}{|c|}{ Real-Time PCR } \\
\hline treatment & $\begin{array}{c}\text { ES- } \\
\text { TRG }\end{array}$ & $\mathrm{n}$ & treatment & $\begin{array}{c}\text { ES- } \\
\text { TRG }\end{array}$ & $\mathrm{n}$ & treatment & $\begin{array}{c}\text { ES- } \\
\text { TRG }\end{array}$ & $\mathrm{n}$ \\
\hline- & - & 7 & - & - & 6 & - & - & 5 \\
\hline $\begin{array}{c}0.9 \% \\
\mathrm{NaCl}\end{array}$ & + & 7 & $\begin{array}{c}0.9 \% \\
\mathrm{NaCl}\end{array}$ & + & 6 & $\begin{array}{c}0.9 \% \\
\text { NaCl }\end{array}$ & + & 5 \\
\hline KYNA-a & + & 7 & KYNA & + & 6 & KYNA & + & 5 \\
\hline & - & & KYNA-a & + & 6 & KYNA-a & + & 5 \\
\hline & & MK-801 & + & 6 & MK-801 & + & 5 \\
\hline
\end{tabular}

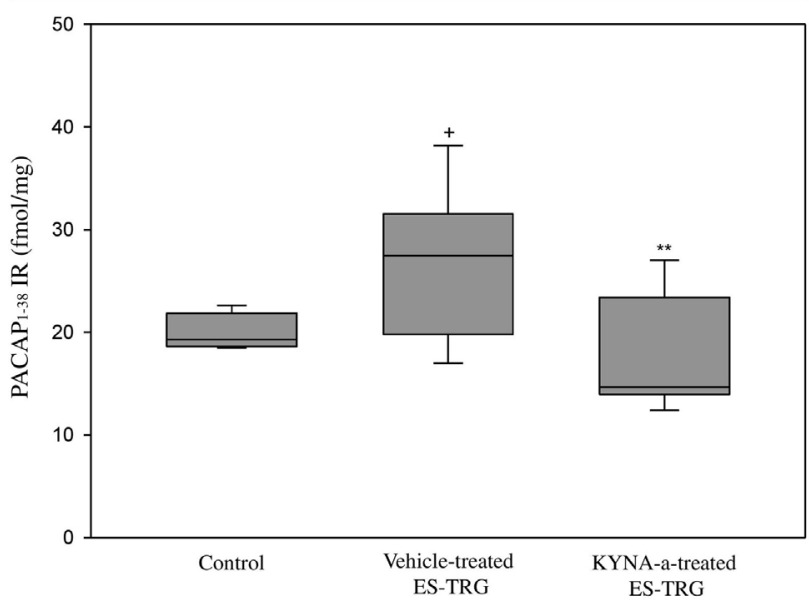

FIGURE 2 | Immunoreactivity of 38 amino acid form of PACAP (PACAP ${ }_{1-38}$ ) in the TNC following electrical stimulation of the trigeminal ganglion. ${ }^{+} p<0.001$ vs. Control group, ${ }^{* *} p<0.005$ vs. Vehicle-treated electrical stimulation of the TRG (ES-TRG) group. Black lines demonstrate medians.

Median \pm interquartile range $(n=7)$. 
The difference of relative optical density between the MK-801and the KYNA-a-treated groups was significant $(p<0.01)$. No significant differences were observed between the KYNA- and KYNA-a-treated groups. No differences were found with either the KYNA or MK-801-treated groups (Figures 3A,B).

\section{Electrical TRG-Stimulation-Induced Increased PACAP ${ }_{1-38}$ mRNA Expression in the TNC Is Prevented by KYNA-a, KYNA, and MK-801 Pretreatment}

A significant increase in the relative mRNA expression of PACAP $_{1-38}$ was observed in the vehicle-treated ES-TRG group (1.162) when compared with the non-stimulated control group (0.987; $p<0.05)$. The relative mRNA expression of PACAP P $_{1-38}$ in the ES-TRG groups pretreated with KYNA (0.804), KYNA-a (0.655; $p<0.01)$, or MK-801 (0.715) were significantly reduced compared with the vehicle-treated ES-TRG group $(p<0.001)$. Comparison of the different pharmacology-treated groups did not reveal any significant difference (Figure 4).

\section{DISCUSSION}

In recent years, a number of clinical studies investigated the possible relevance of PACAP in migraine. In patients suffering from migraines without aura, the development of PACAP ${ }_{1-38}$-evoked

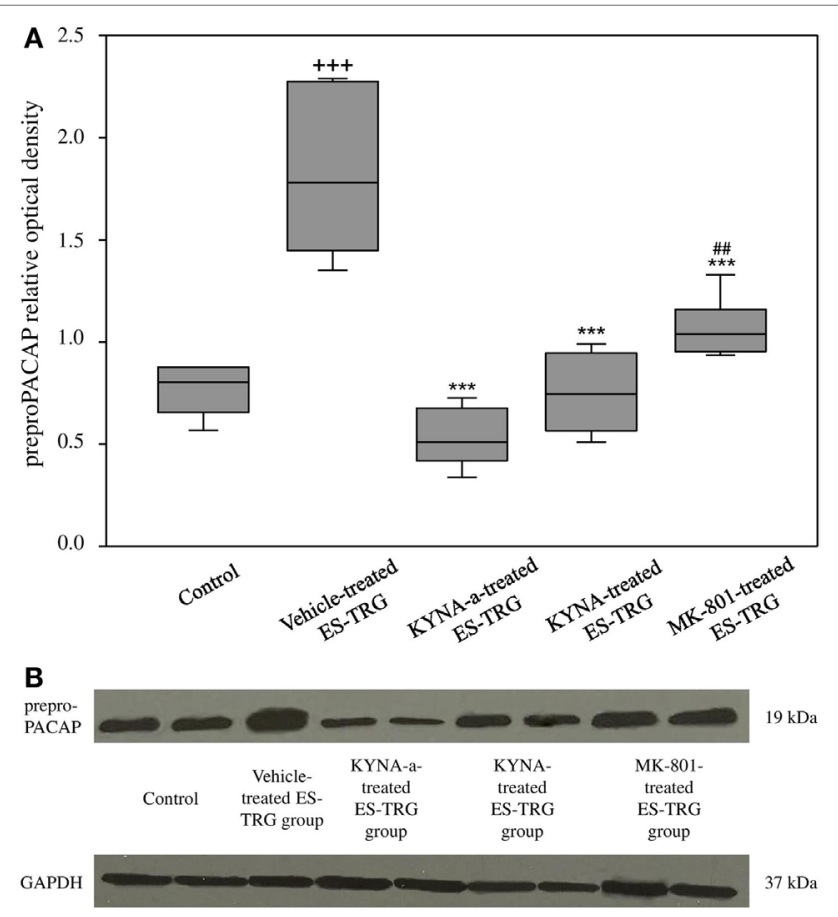

FIGURE 3 | (A) Relative optical density of the preproPACAP protein in the TNC following electrical stimulation of the trigeminal ganglion. ${ }^{+++} p<0.001$ vs. Control group. ${ }^{\star \star \star} p<0.001$ vs. Vehicle-treated electrical stimulation of the TRG (ES-TRG) group. \# $p<0.01$ vs. kynurenic acid synthetic analog (KYNA-a)-treated ES-TRG group. Black lines demonstrate medians. Median \pm interquartile range $(n=6)$. (B) Western blot of preproPACAP and glyceraldehyde 3-phosphate dehydrogenase (GAPDH) expression in the TNC. migraine-like attack was independent of the severity of family load (21). In the same study, 90 min after the injection, the levels of numerous markers relevant in the disease (such as vasoactive intestinal polypeptide, prolactin, $\mathrm{S} 100 \mathrm{~B}$, and thyroid-stimulating hormone) were increased in the plasma (22). In addition, magnetic resonance imaging angiography examinations revealed that PACAP $_{1-38}$-induced headache was associated with prolonged vasodilatation of the middle meningeal artery (MMA), but not the middle cerebral artery (MCA) (23). The serotonin 5-HT1B/D receptor agonist, sumatriptan, was able to alleviate the headache, which mirrored the contraction of the MMA, but not the MCA, suggesting that $\mathrm{PACAP}_{1-38}$-induced headaches may arise from the extracerebral arteries (23). These human and experimental data suggest that PACAP may be a key molecule in the pathomechanism of migraine.

Several lines of evidence reflect that abnormality of the kynurenine pathway plays roles in several diseases (24). Results of animal experiments suggest a link between the kynurenine pathway and migraine. Indeed, several studies have demonstrated that the NMDAR inhibitor KYNA and its analogs have antinociceptive effects at the levels of both first- and second -order sensory neurons (25). In the animal model of CFAinduced TS activation, KYNA and one of its derivatives both decreased the levels of several inflammatory mediators in the TRG (26). Recently, the effects of two KYNA analogs have been tested in the orofacial formalin model, revealing that the two analogs were able to inhibit the formalin-induced behavioral and morphological changes, and increased the concentration of KYNA in the rat TNC (27). Notably, systemic administration of NTG decreased the expression of kynurenine aminotransferase II in the TS of rats, an enzyme catalyzing the transformation of L-kynurenine to KYNA (28). In line with this, in another

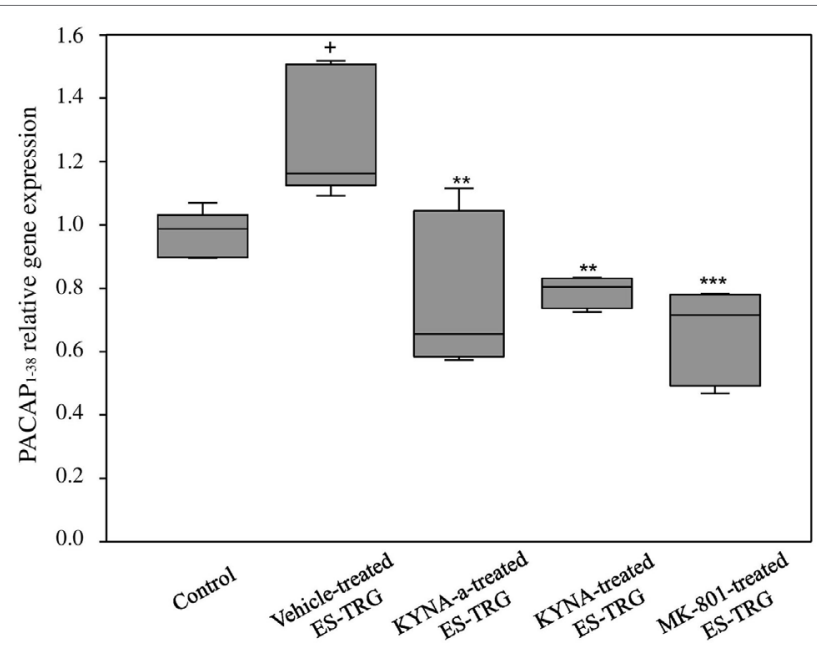

FIGURE 4 | Relative mRNA expression of 38 amino acid form of PACAP $\left(\mathrm{PACAP}_{1-38}\right)$ in the TNC following electrical stimulation of the trigeminal ganglion. ${ }^{+} p<0.05$ vs. Control group. ${ }^{* *} p<0.01$ vs. Vehicle-treated electrical stimulation of the TRG (ES-TRG) group. ${ }^{* \star *} p<0.001$ vs. Vehicle-treated ES-TRG group. Black lines demonstrate medians. Median \pm interquartile range $(n=5)$. 
model of TS activation, decreased KAT immunoreactivity was observed in mast cells, Schwann cells, and dural macrophages (29). Besides animal experimental data, clinical results have also provided evidence for the connection between the kynurenine system and various headache disorders, including migraine. Indeed, in patients suffering from cluster headache or chronic migraine, alterations of the kynurenine pathway were observed, which among others manifested in the reduction of KYNA concentration in the serum (30).

Based on the consistent data linking glutamatergic transmission (especially through NMDARs), the kynurenine pathway and PACAP to the pathogenesis of migraine, this is the first study that investigated the relationship between these systems. Findings that all proposed antagonists of the NMDAR were used here (KYNA, KYNA-a and the reference compound MK-801) decreased the expression of PACAP, both at the levels of proteome and transcriptome. One of innovation of this study, that KYNA-a can downregulate both protein and gene expression of preproPACAP and PACAP ${ }_{1-38}$, suggesting that KYNA-a is a potential new drug in the PACAP-targeted migraine therapy in the future. However, the excessive reduction of PACAP expression level should be considered. It is crucial and hard to find the optimal concentration of this peptide, because shifting in the PACAP balance can lead to several symptoms (protective vs. harmful effects) due to the pleiotropic nature of this peptide. To reveal the long-term effects of PACAP in the migraine is needs further investigations. Our results are consistent with previous studies, which reported that the main mediator of PACAP gene expression is intracellular calcium homeostasis (19). Indeed, besides the action of voltagedependent calcium channels, the main inducer of PACAP gene expression is calcium influx through the NMDARs. The drugs used in our experiment block the NMDAR, thereby moderating the amount of calcium coming into the cell, which may result in decreased PACAP gene expression. The proposed mechanism for the regulation of PACAP gene expression is presented in Figure 5. The other interesting observation of this study that the expression levels of preproPACAP are significantly different between the MK-801- and the KYNA-a-treated groups, raises the possibility of the involvement of additional KYNA targets besides NMDA. Our opinion is that the differences between the variant drug-treated groups are based on the receptor specificity of the molecules. There is evidence that besides NMDAR, KYNA has an effect on the AMPA, kainate, aryl hydrocarbon, G protein-coupled receptor 35, and opiate receptor (31). Regarding KYNA-a, investigations are in process, but the exact targets and mechanisms of this analog have not yet been identified. Presumably, KYNA-a has similar targets to the base compound. Our findings raise the role of these receptors in migraine and draw attention to the importance of further examinations (Figure 5).

In other studies, associations between these systems have also been revealed. Immunohistochemical data suggest a possible interaction between glutamatergic, PACAP, and CGRP systems, based on the expression pattern of PACAP and glutamate in the TRG (32). In addition, a study investigating contextual fear

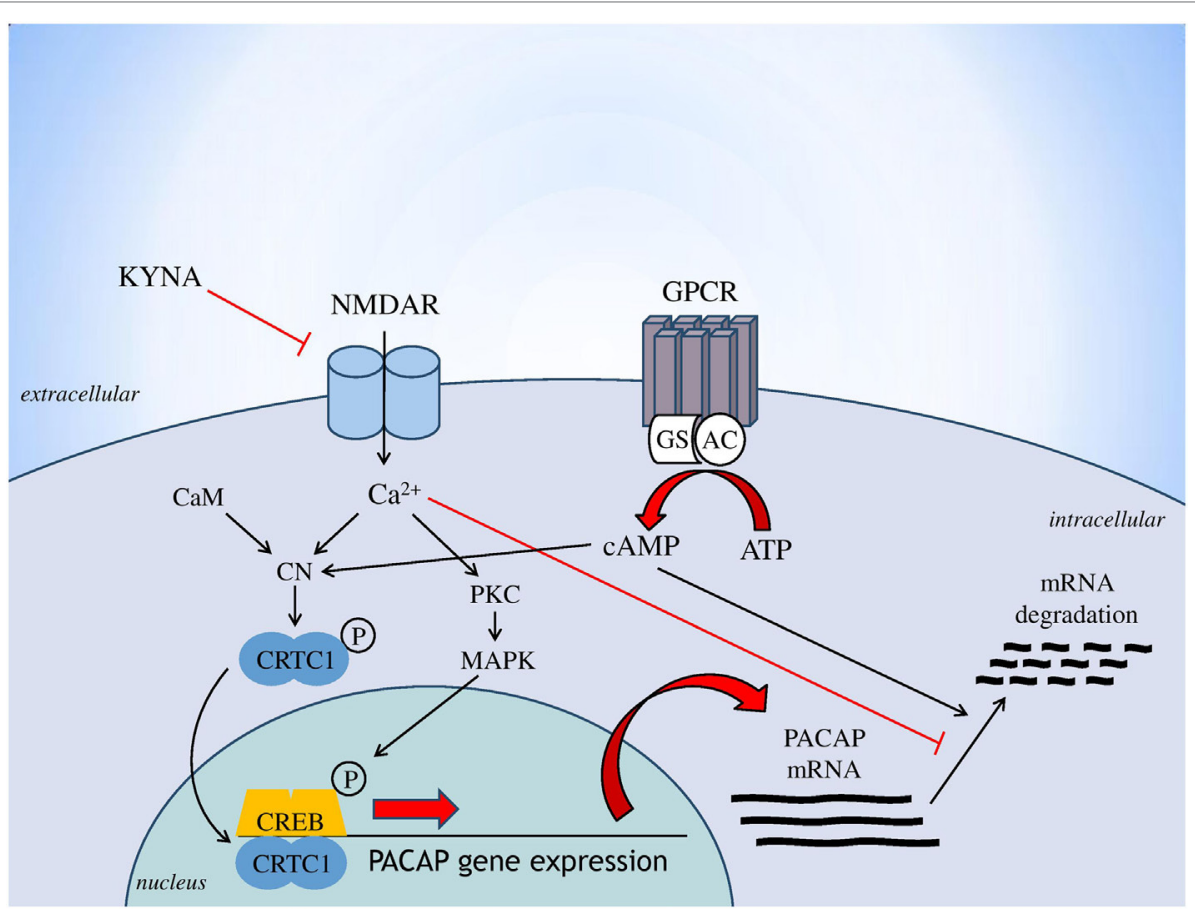

FIGURE 5 | Regulation of PACAP gene expression [based on Fukuchi et al. (19), genes to cells]. Abbreviations: AC, adenylate cylase; ATP, adenosine monophosphate; CaM, calmodulin; cAMP, cyclic adenosine monophosphate; CN, calcineurin; CREB, cAMP response element binding protein; CRTC1, CN/Cre binding protein; GPCR, G protein-coupled receptor; Gs, stimulatory G protein; KYNA, kynurenic acid; MAPK, mitogen-activated protein kinase; NMDAR, N-methylD-aspartate glutamate receptor; PKC, protein kinase C; PACAP, pituitary adenylate cyclase-activating polypeptide. 
conditioning in rats reported that PACAP participated in the consolidation and extinction via NMDARs (33).

Our results provided the direct evidence that NMDAR inhibition can prevent the overexpression of PACAP in an experimental model of migraine and support the idea that therapies aimed at the modulation of glutamatergic transmission, including the use of KYNA derivatives, may be of therapeutic value in migraine. These data contribute to the better understanding of migraine pathogenesis and thereby to the development of more efficient therapeutic approaches.

\section{ETHICS STATEMENT}

All experimental procedures performed in this study complied fully with the guidelines of Act 1998/XXVIII of the Hungarian Parliament on Animal Experiments (243/1988) and with the recommendations of the International Association for the Study of Pain and European Communities Council (86/609/ECC). The studies were in harmony with the Ethical Codex of Animal Experiments and were approved by the Ethics Committee of the Faculty of Medicine, University of Szeged, XXIV./352/2012.

\section{AUTHOR CONTRIBUTIONS}

TK: participated in the design and implementation of experiments, and statistical analysis, interpreted data and wrote the manuscript; BT: participated in the implementation of the experiments and statistical analysis; JT: participated in the conception and design of the experiments, the interpretation of the data, and writing; all the authors: critical revision of the manuscript; TB: participated in RIA measurements; FF: synthesized KYNA-a; ZH: participated in coordinating RIA measurements, in the final approval of the version to be published; LV: participated in the design of the experiments and in the final approval of the version to be published.

\section{ACKNOWLEDGMENTS}

This work was supported by the projects EUROHEADPAINFP7Health 2013-Innovation; Grant No. 602633; GINOP-2.3.2-152016-00034, KTIA_NAP_13-2014-0022, and GINOP-2.3.2-152016-00048. The authors are grateful to Jennifer Tusz for his valuable contribution in proofreading the manuscript.

\section{REFERENCES}

1. Ashina M, Hansen JM, Olesen J. Pearls and pitfalls in human pharmacological models of migraine: 30 years' experience. Cephalalgia (2013) 33(8):540-53. doi:10.1177/0333102412475234

2. Gormley P, Anttila V, Winsvold BS, Palta P, Esko T, Pers TH, et al. Metaanalysis of 375,000 individuals identifies 38 susceptibility loci for migraine. Nat Genet (2016) 48(8):856-66. doi:10.1038/ng.3598

3. Palkovits M, Somogyvari-Vigh A, Arimura A. Concentrations of pituitary adenylate cyclase activating polypeptide (PACAP) in human brain nuclei. Brain Res (1995) 699(1):116-20. doi:10.1016/0006-8993(95)00869-R

4. Pietrobon D, Moskowitz MA. Pathophysiology of migraine. Annu Rev Physiol (2013) 75:365-91. doi:10.1146/annurev-physiol-030212-183717

5. Tajti J, Uddman R, Edvinsson L. Neuropeptide localization in the "migraine generator" region of the human brainstem. Cephalalgia (2001) 21(2):96-101. doi:10.1046/j.1468-2982.2001.00140.x

6. Tajti J, Uddman R, Moller S, Sundler F, Edvinsson L. Messenger molecules and receptor mRNA in the human trigeminal ganglion. J Auton Nerv Syst (1999) 76(2-3):176-83. doi:10.1016/S0165-1838(99)00024-7

7. Tuka B, Helyes Z, Markovics A, Bagoly T, Szolcsanyi J, Szabo N, et al. Alterations in PACAP-38-like immunoreactivity in the plasma during ictal and interictal periods of migraine patients. Cephalalgia (2013) 33(13):1085-95. doi:10.1177/0333102413483931

8. Lassen LH, Haderslev PA, Jacobsen VB, Iversen HK, Sperling B, Olesen J. CGRP may play a causative role in migraine. Cephalalgia (2002) 22(1):54-61. doi:10.1046/j.1468-2982.2002.00310.x

9. Schytz HW, Birk S, Wienecke T, Kruuse C, Olesen J, Ashina M. PACAP38 induces migraine-like attacks in patients with migraine without aura. Brain (2009) 132(Pt 1):16-25. doi:10.1093/brain/awn307

10. Schytz HW, Olesen J, Ashina M. The PACAP receptor: a novel target for migraine treatment. Neurotherapeutics (2010) 7(2):191-6. doi:10.1016/j. nurt.2010.02.003

11. Vecsei L, Tuka B, Tajti J. Role of PACAP in migraine headaches. Brain (2014) 137(Pt 3):650-1. doi:10.1093/brain/awu014

12. Markovics A, Kormos V, Gaszner B, Lashgarara A, Szoke E, Sandor K, et al. Pituitary adenylate cyclase-activating polypeptide plays a key role in nitroglycerol-induced trigeminovascular activation in mice. Neurobiol Dis (2012) 45(1):633-44. doi:10.1016/j.nbd.2011.10.010

13. Tuka B, Helyes Z, Markovics A, Bagoly T, Nemeth J, Mark L, et al. Peripheral and central alterations of pituitary adenylate cyclase activating polypeptide-like

immunoreactivity in the rat in response to activation of the trigeminovascular system. Peptides (2012) 33(2):307-16. doi:10.1016/j.peptides.2011.12.019

14. Vecsei L, Szalardy L, Fulop F, Toldi J. Kynurenines in the CNS: recent advances and new questions. Nat Rev Drug Discov (2013) 12(1):64-82. doi:10.1038/ $\operatorname{nrd} 3793$

15. Fejes-Szabo A, Bohar Z, Vamos E, Nagy-Grocz G, Tar L, Veres G, et al. Pre-treatment with new kynurenic acid amide dose-dependently prevents the nitroglycerine-induced neuronal activation and sensitization in cervical part of trigemino-cervical complex. J Neural Transm (Vienna) (2014) 121(7):725-38. doi:10.1007/s00702-013-1146-2

16. Knyihar-Csillik E, Mihaly A, Krisztin-Peva B, Robotka H, Szatmari I, Fulop F, et al. The kynurenate analog SZR-72 prevents the nitroglycerol-induced increase of c-fos immunoreactivity in the rat caudal trigeminal nucleus: comparative studies of the effects of SZR-72 and kynurenic acid. Neurosci Res (2008) 61(4):429-32. doi:10.1016/j.neures.2008.04.009

17. VamosE, Fejes A, Koch J, TajtiJ, Fulop F, Toldi J, etal.Kynurenatederivative attenuates the nitroglycerin-induced CamKIIalpha and CGRP expression changes. Headache (2010) 50(5):834-43. doi:10.1111/j.1526-4610.2009.01574.x

18. Lukacs M, Warfvinge K, Kruse LS, Tajti J, Fulop F, Toldi J, et al. KYNA analogue SZR72 modifies CFA-induced dural inflammation-regarding expression of pERK1/2 and IL-1beta in the rat trigeminal ganglion. J Headache Pain (2016) 17(1):64. doi:10.1186/s10194-016-0654-5

19. Fukuchi M, Kuwana Y, Tabuchi A, Tsuda M. Balance between cAMP and $\mathrm{Ca}(2+)$ signals regulates expression levels of pituitary adenylate cyclase-activating polypeptide gene in neurons. Genes Cells (2016) 21(8):921-9. doi:10.1111/gtc. 12393

20. Mabuchi T, Shintani N, Matsumura S, Okuda-Ashitaka E, Hashimoto H, Muratani T, et al. Pituitary adenylate cyclase-activating polypeptide is required for the development of spinal sensitization and induction of neuropathic pain. J Neurosci (2004) 24(33):7283-91. doi:10.1523/JNEUROSCI.0983-04.2004

21. Guo S, Vollesen AL, Hansen RD, Esserlind AL, Amin FM, Christensen AF, et al. Part I: pituitary adenylate cyclase-activating polypeptide- 38 induced migraine-like attacks in patients with and without familial aggregation of migraine. Cephalalgia (2017) 37(2):125-35. doi:10.1177/0333102416639516

22. Guo S, Vollesen AL, Hansen YB, Frandsen E, Andersen MR, Amin FM, et al. Part II: biochemical changes after pituitary adenylate cyclase-activating polypeptide-38 infusion in migraine patients. Cephalalgia (2017) 37(2):136-47. doi:10.1177/0333102416639517

23. Amin FM, Asghar MS, Guo S, Hougaard A, Hansen AE, Schytz HW, et al. Headache and prolonged dilatation of the middle meningeal artery 
by PACAP38 in healthy volunteers. Cephalalgia (2012) 32(2):140-9. doi:10.1177/0333102411431333

24. Lovelace MD, Varney B, Sundaram G, Lennon MJ, Lim CK, Jacobs K, et al. Recent evidence for an expanded role of the kynurenine pathway of tryptophan metabolism in neurological diseases. Neuropharmacology (2017) 112(Pt B):373-88. doi:10.1016/j.neuropharm.2016.03.024

25. Pardutz A, Fejes A, Bohar Z, Tar L, Toldi J, Vecsei L. Kynurenines and headache. J Neural Transm (Vienna) (2012) 119(2):285-96. doi:10.1007/ s00702-011-0665-y

26. Csati A, Edvinsson L, Vecsei L, Toldi J, Fulop F, Tajti J, et al. Kynurenic acid modulates experimentally induced inflammation in the trigeminal ganglion. J Headache Pain (2015) 16:99. doi:10.1186/s10194-015-0581-x

27. Veres G, Fejes-Szabo A, Zadori D, Nagy-Grocz G, Laszlo AM, Bajtai A, et al. A comparative assessment of two kynurenic acid analogs in the formalin model of trigeminal activation: a behavioral, immunohistochemical and pharmacokinetic study. J Neural Transm (Vienna) (2017) 124(1):99-112. doi:10.1007/ s00702-016-1615-5

28. Nagy-Grocz G, Tar L, Bohar Z, Fejes-Szabo A, Laborc KF, Spekker E, et al. The modulatory effect of anandamide on nitroglycerin-induced sensitization in the trigeminal system of the rat. Cephalalgia (2016) 36(9):849-61. doi:10.1177/0333102415613766

29. Knyihar-Csillik E, Chadaide Z, Okuno E, Krisztin-Peva B, Toldi J, Varga C, et al. Kynurenine aminotransferase in the supratentorial dura mater of the rat: effect of stimulation of the trigeminal ganglion. Exp Neurol (2004) 186(2):242-7. doi:10.1016/j.expneurol.2003.12.001
30. Curto M, Lionetto L, Negro A, Capi M, Fazio F, Giamberardino MA, et al. Altered kynurenine pathway metabolites in serum of chronic migraine patients. J Headache Pain (2015) 17:47. doi:10.1186/s10194-016-0638-5

31. Dezsi L, Tuka B, Martos D, Vecsei L. Alzheimer's disease, astrocytes and kynurenines. Curr Alzheimer Res (2015) 12(5):462-80. doi:10.2174/1567205 01205150526114000

32. Eftekhari S, Salvatore CA, Johansson S, Chen TB, Zeng Z, Edvinsson L. Localization of CGRP, CGRP receptor, PACAP and glutamate in trigeminal ganglion. Relation to the blood-brain barrier. Brain Res (2015) 1600:93-109. doi:10.1016/j.brainres.2014.11.031

33. Schmidt SD, Myskiw JC, Furini CR, Schmidt BE, Cavalcante LE, Izquierdo I. PACAP modulates the consolidation and extinction of the contextual fear conditioning through NMDA receptors. Neurobiol Learn Mem (2015) 118:120-4. doi:10.1016/j.nlm.2014.11.014

Conflict of Interest Statement: The authors declare that the research was conducted in the absence of any commercial or financial relationships that could be construed as a potential conflict of interest.

Copyright (c) 2018 Körtési, Tuka, Tajti, Bagoly, Fülöp, Helyes and Vécsei. This is an open-access article distributed under the terms of the Creative Commons Attribution License (CC BY). The use, distribution or reproduction in other forums is permitted, provided the original author(s) or licensor are credited and that the original publication in this journal is cited, in accordance with accepted academic practice. No use, distribution or reproduction is permitted which does not comply with these terms. 